\title{
Novas sobre Álvaro Cunqueiro na Galicia de posguerra. Actividades na Asociación Cultural Iberoamericana de A Coruña desde 1951
}

\author{
Olivia RodRíGUEZ GONZÁlEZ \\ Universidade da Coruña \\ olivia@udc.es \\ Recibido: mayo 2012. Aceptado: junio 2012
}

\begin{abstract}
Resumo: Álvaro Cunqueiro é unha das figuras clave da cultura galega da posguerra, cuxa pegada é hoxe aínda pantente. Aínda que sufrise a represión do Réxime nas súas carnes, non deixou de desenvolver unha importante actividade nomeadamente xornalística ao longo de varias décadas, ben como de promoción cultural na Asociación Cultural Iberoamericana a partir de 1951.
\end{abstract}

Palabras clave: Álvaro Cunqueiro, xornalista, activista, Asociación Cultural Iberoamericana.

Resumen: Álvaro Cunqueiro es una de las figuras clave de la cultura galega de la posguerra, cuya huella sigue siendo todavía hoy bien visible. Aunque sufrió la represión del Régimen en sus carnes, no dejó por ello de desarrollar una importante actividad sobre todo periodística a lo largo de varias décadas, así como de promoción cultural en la Asociación Cultural Iberoamericana a partir de 1951.

Palabras clave: Álvaro Cunqueiro, periodista, activista, Asociación Cultural Iberoamericana.

\section{OS MOTIVOS DO REGRESO DE CUNQUEIRO A GALICIA}

Álvaro Cunqueiro chega a Mondoñedo en 1947 e ata 1964 -data na que é nomeado director de Faro de Vigo, onde viña colaborando dende $1962^{1}$ - non se considera finalizado un ostracismo que comeza oficialmente o 23 de xuño de 1944, cando é expulsado do Rexistro Oficial de Periodistas, ao que pertencía desde 1938 (Franco 1991: 566).

1 Precisamente, e xulgamos existir unha relación entre os dous feitos, no verán de 1962 Manuel Fraga Iribarne é nomeado Ministro de Información e Turismo, tras a destitución de Arias Salgado co gallo dos sucesos do chamado - por ocorrencia de Fraga, precisamente-»Contubernio de Munich». 
Bastantes anos despois, un relatorio da Dirección General de Seguridad do Ministerio de Gobernación, enviado ao Ministerio de Información e Turismo o 23 de febreiro de $1970^{2}$, dá conta dos sumarios que lle abriron a Cunqueiro por delito de estafa: o primeiro, en agosto de 1944; os dous seguintes, por estafa á editorial Morata, en decembro de 1946; e ás Gráficas Clemares en marzo de 1947. En xuño e en agosto dese ano, de novo é imputado pola subtracción de impresos para cometer estafas. En setembro de 1947 é denunciado por Carmen Prida Casas $^{3}$ por apropiación indebida de alfaias e de 12 mil ptas. obtidas da venda duns aparellos de verbena propiedade da denunciante. As causas seguiron abrollando, pois á Audiencia Territorial de Madrid «interesa saber onde ten o seu domicilio» en 1951 e, en maio dese ano, o Goberno Civil de Lugo comunica que ingresou na Prisión Provincial da devandita capital, quedando a disposición de dous xulgados de Madrid.

O relatorio, que non detalla cal foi a resolución xudicial dos casos, anota outros pormenores que, por diferentes vías de vixilancia policial, chegan a esa Dirección. Así, indícase que en maio de 1966 Cunqueiro figura como membro da Asociación Cultural Iberoamericana da Coruña, entidade que «ten como fin efectuar intercambios culturais cos países Hispanoamericanos» (A.G.A. 1970).

\section{A LENDA E OS FEITOS HISTÓRICOS}

Imos seguir a actividade intelectual de Cunqueiro desde o desterro á terra natal, un feito que pode parangonarse, salvando as grandes diferenzas, co de Dionisio Ridruejo ${ }^{4}$, a ovella negra do Réxime, mais o único que se podía permitir o atrevemento de cantarlle as corenta a un ditador que non quixo ou non puido facelo desaparecer. Á volta da División Azul, Ridruejo é desterrado a Sant Cugat, momento no que Álvaro Cunqueiro e el coinciden na Redacción da revista Destino de Barcelona.

Camilo José Cela vive unha experiencia similar, pois tamén el se ve despoxado do carné de periodista en Madrid por Juan Aparicio, Director Xeral de Prensa. Tras un período de acumulación de méritos para volver ao rego oficial, decide marchar a Palma de Mallorca, sen que haxa indicio de causa por delito ningún nin de desterro forzado. Aínda así, os motivos que o apartan de Madrid

2 Pedíase información sobre o cadro de persoal do periódico Nivel, onde figuraban tamén Emilio López Valls, Germán Álvarez González e Julián Ayesta. Este xornal, dirixido por Mauro Muñiz, só publicou un número, en decembro de 1969, pois foi clausurado polo Alfredo Sánchez Bella, ministro de Información e Turismo. Mauro Muñiz revela a causa: «Titulamos a cuatro columnas con el robo de unas cañoneras francesas en Oriente Medio, una primera editorial, y, finalmente, el discurso de Franco a tres columnas. El caso es que fue prohibido el 31 de diciembre de 1969: el discurso del jefe del Estado no era la noticia principal.» (Guillot 2007).

3 Casada con Guillermo Núñez Rodríguez, marino mercante e alférez provisional con Medalla Militar Naval colectiva, tal como reza a súa esquela no $A B C$ do 26 de febreiro de 1981, polo seu falecemento o 21 de febreiro dese ano. Ela morrería en marzo de 1987.

${ }_{4}$ Cando volve a Madrid a finais de setembro de 1951, ocupa postos nas xuntas de instituto de Estudios Políticos, Museo Nacional de Arte Moderno, Asociación Cultural Iberoamericana e Instituto de Cultura Hispánica (Gracia 2008: 126). 
explícanse pola marxinación á que o somete o grupo falanxista que dirixía a empresa periodística do Réxime.

A experiencia de expulsión do grupo de Falanxe encargado da prensa franquista non era excepcional, como vemos. Tampouco irreversible, pois os tres suxeitos citados tiñan un estatuto de privilexio «conxelado» pero evidente ${ }^{5}$ e se algo tiñan que temer era a cambadela ou a agresión por parte de membros de faccións diferentes dentro do conglomerado de orixe magmática que era o franquismo cultural.

Centrándonos en Álvaro Cunqueiro, podemos advertir que a lenda do castigo por picaresca bohemia e do ostracismo autoimposto en época de desgraza sentimental empezou desde o mesmo momento en que regresa a Mondoñedo. Así o rememora Mariano Tudela nun artigo publicado con motivo do Día das Letras dedicado a Cunqueiro:

«En La Coruña, donde yo vivía, algunos amigos -Antonio Molina, Fernando Mon, mi primo Paco Tudela y un curioso personaje boliviano llamado Raúl Calvimontes- trataban de sacarlo del voluntario ostracismo y lo llamaban con frecuencia para pronunciar conferencias, que siempre resultaban admirables. Así, Álvaro podía cobrar las exiguas pesetas - mil ya era una bonita cifra- con las que se recompensaba al conferenciante. Por ilustre que fuera, como en este caso.

Leíamos Mar ao norde, Poemas de si e non, Balada de las damas del tiempo pasado. Una vez me dedicó Cantiga nova que se chama riveira, que hoy conservo en mi biblioteca en lugar de honor, con una hermosa cantiga de amigo manuscrita en las primeras páginas. Comíamos y bebíamos vino del país con José María Castroviejo, con Álvaro Cebreiro, con Urbano Lugrís. Tiempos de delicia que nunca volverán.» (Tudela 1991 a).

A guerra, segue a dicir noutro lugar Mariano Tudela, fíxolle a Cunqueiro un fraco favor. E insiste na lenda: aos dez anos de vivir en Madrid:

«[...] hastiado de intrigas y del permanente do ut des para no perderse la foto en la que siempre suelen salir los mismos, Álvaro regresó un día a Mondoñedo, a su reencuentro con la paz, la soledad y el tiempo ancho y abierto.» (Tudela 1991 b: 55).

Na cidade permanecía días e ás veces semanas, deleitando os tertulianos do Café Galicia, La Granja ou o Cantón Bar, e gozando das tabernas Salto do Can, O Crego e Casa Enrique.:

«Junto a la torre (...) nos hablaba de Hércules, de Gerión, para luego mirar al horizonte y narrarnos historias de Merlín, Perceval, Artús y doña Ginebra» (Tudela 1991 b: 56).

5 Por exemplo, Dionisio Ridruejo, malia ser encarcerado en febreiro de 1956 e verse obrigado a dimitir en setembro do mesmo ano como director de Radio Continental, pode seguir vivindo en Madrid, onde Juan Aparicio lle volve entregar o carnét de periodista (Gracia 2008:128). 
A Coruña, asegura o escritor citado, sacouno quizais ao seu pesar de Mondoñedo, pero redimiuno do silencio para levalo á notoriedade pública, especialmente cando empezou a escribir en La Voz de Galicia e a súa sona medrou fóra dos círculos culturais.

\section{ORIXE E FUNDACIÓN DA ASOCIACIÓN CULTURAL IBEROAMERI- CANA DA CORUÑA}

A Asociación Cultural Iberoamericana de Coruña fúndase o 1 de outubro de 1950 por iniciativa de Pascual-Luis Gantes de Boado, avogado e membro da «Sociedad Española de Estudios Internacionales y Coloniales» de Madrid, e permanece en funcionamento ata 1976. A A.C.I. coruñesa, como as xurdidas anteriormente nas provincias de Valladolid, Murcia, Salamanca, Granada, Sevilla, Bilbao, e como o «Instituto de Estudios Hispánicos» en Barcelona, ten a súa orixe no Instituto de Cultura Hispánica.

Durante o XIX Congreso Internacional da Pax Romana, celebrado no mosteiro de San Lorenzo de El Escorial, os asistentes hispanoamericanos reúnense en asemblea especial e propoñen o 3 de xullo de 1946, a través de Ramón Sánchez Medal, representante de México, a fundación do Instituto Cultural Hispanoamericano, que aspira a instituír sedes en cada unha das capitais iberoamericanas.

O I.C.H. constitúese como un organismo do Ministerio de Asuntos Exteriores, con Joaquín Ruiz-Giménez como primeiro director, e dispón de entidades anexas como o Colexio Maior Nuestra Señora de Guadalupe para universitarios hispanoamericanos, a Cátedra Ramiro de Maeztu na Universidade de Madrid, e as publicacións Mundo Hispánico, Cuadernos Hispanoamericanos, Información Hispánica, Mensaje e Alférez.

Como rama española do Instituto créase a Asociación Cultural Iberoamericana de Madrid, entidade de regulamento autónomo, que repite nos seus estatutos ao pé da letra os fins do I.C.H., sendo o primeiro dedicarse:

«a) Al fomento y desarrollo de la cultura española e hispanoamericana, en todos sus grados y aspectos, a la luz del ideal católico de la vida y de la gloriosa tradición de los pueblos hispánicos.

b) A la defensa y exaltación de esa cultura y su eficaz proyección sobre otros pueblos no hispánicos.

c) $\mathrm{Al}$ apoyo de todas las iniciativas fecundas y mecenazgos de todas las personas valiosas que puedan contribuir a dichos crecimientos y expansión de la cultura hispanoamericana.» (A.C.I., 44843)

Con sede na antiga Residencia de Estudantes, a A.C.I. consta dunha sección de profesores e outra universitaria ou de estudantes, e admite a creación de futuras seccións autónomas e de filiais en distintos lugares de España. Pedro Laín Entralgo é o presidente e Víctor de la Serna, o secretario. Outros cargos son de- 
sempeñados por José Ignacio Escobar -marqués de las Marismas-, Martín González del Valle, Alfredo Sánchez Bella e Francisco Sintes Obrador. A sección universitaria está presidida por José María Valverde e actúa nela como secretario Carlos Robles Piquer. Outros cargos recaen en Miguel Sánchez Mazas e José Fraga Iribarne.

\section{CONSTITUCIÓN DA ASOCIACIÓN CULTURAL IBEROAMERICANA DA CORUÑA}

Créase a seguir a A.C.I. en Coruña coa pretensión de ser unha «entidade colaboradora e adherida» ao I.C.H. con sede en Madrid. A primeira Xunta Directiva ten como presidente o arquitecto e fiscal da vivenda, Juan González Cebrián $^{6}$; e como secretario, Pascual-Luis Gantes de Boado. Nos cargos de vicepresidente e tesoureiro, respectivamente, hai un tenente coronel do Estado Maior, Francisco del Valle Carlos-Roca e un coronel de infantería, José Enseñat Soler. Un licenciado en ciencias exactas, Jesús García Siso, actúa como vicesecretario. E figuran como contador, o avogado fiscal Antonio Couceiro Tovar; e como arquiveiro, o director da Biblioteca Provincial, Miguel González Garcés. Entre os varios vocais que se nomean, os dous primeiros son designados para formar parte da Comisión Executiva: o de Protocolo, o procurador Fernando Mon. E o de Exposicións e Certames, o escritor Mariano Tudela. O resto dos vogais son os directores de La Voz de Galicia e de El Ideal, así como Enrique Mariñas, Urbano Lugrís, Rodrigo A. de Santiago, Francisco José de La Colina, Luis Monteagudo, Amando Ossorio, etc.

Na sección universitaria atópanse os moi activos membros José Luis Alonso Zato, Gabriel Alonso e Emilio Quesada. A A.C.I. conta tamén cunha «Sección Femenina» que dirixe Dolores López-Acedo.

Hai unha nómina de 50 socios fundadores, con Pascual Luis Gantes de Boado á cabeza, seguido de Mariano Tudela, Luis Monteagudo, os músicos Rafael Vázquez Sebastiá e José Béjar Vázquez, Álvaro Cebreiro (o antano redactor xunto con Manuel Antonio, do manifesto «Mais alá!»), Abelardo Suárez Zas (da familia do alcalde Suárez Ferrín, asasinado na guerra), e moitos máis. Con estes 50 socios, quixo Gantes de Boado asegurar o funcionamento da A.C.I. nos primeiros momentos da súa vida. A finais de 1951 cóntanse un total de 267 socios, entre fundadores e colaboradores: «Intelectuais», 168; «Sección Universitaria», 25; «Sección Feminina colaboradora», 74; e «Socios protectores», 4. No rexistro de 1954 hai un total de 595 socios, dos que 200 son mulleres.

6 Os presidentes sucesivos das directivas renovadas cada dous anos, foron: Juan González Cebrián, Luis Julio Vázquez-Pena Núñez, Jesús Pintos Pérez, Miguel González Garcés, Enríque Míguez Tapia, e de novo González Garcés. 


\section{INAUGURACIÓN E INMEDIATA CRISE ECONÓMICA}

A inauguración tivo lugar no salón de plenos do Concello da Coruña o 9 de xuño de 1951, con asistencia do director do Instituto de Cultura Hispánica, Alfredo Sánchez Bella (que asemade era o secretario xeral da Organización Internacional de Universitarios Católicos Pax Romana), e autoridades relixiosas, militares, académicas, diplomáticas e civís ${ }^{7}$. Manuel Fraga Iribarne, daquela Subdirector do Seminario de Problemas Hispanoamericanos, escusou, lamentándoo, a súa ausencia por acharse nun congreso en Francia.

Practicamente desde o día en que os membros da directiva solicitan unha cantidade desorbitada a Alfredo Sánchez Bella, que contesta que o Instituto non concede cantidades superiores a 24 mil ptas., e menos para sufragar actos de inauguración. O director do I.C.H. vailles advertir repetidas veces que os cartos cos que os poden subvencionar non van serlles abondos, e que deben completalos con achegas do Concello e de «aquellos que hayan estado en Hispanoamérica», é dicir, os «emigrantes retornados» que se designaban co eufemismo de «ex-residentes en Hispanoamérica» (A.C.I. 44851).

Non foron só os gastos de inauguración e das actividades celebradas desde o ano1951 as que ocasionaron unha creba económica que non deixou de perseguir a A.C.I. coruñesa desde os inicios. O que resultou verdadeiramente custoso foi a preparación e mantemento do local social, un sétimo piso na rúa Emilia Pardo Bazán, no edificio do Instituto de Previsión Social, que a A.C.I. alugou por 1.200 ptas. en marzo de 1951. Axiña se viron incapaces os directivos de atender ao pago mensual, de xeito que a finais de 1953 debían máis de 18 mil ptas.

A decoración do local foi realizada por Urbano Lugrís, tamén autor do deseño dos programas e cartaces dos actos. Os murais desapareceron co peche do $\mathrm{local}^{8}$. Pintores como María Antonia Dans, Gloria de Llano, Mariano García Patiño, Antonio Lago Rivera e Antonio López cederon obras para ser colgadas nas dependencias. Ademais de ter á súa disposición, cunha especie de vales, un restaurante próximo co que se chegou a un acordo, o mobiliario encargado a «Mueblería Cervigón» incluía os elementos dun bar a todo luxo para as reunións da A.C.I.. Este comercio converteríase no principal e máis duradeiro acredor por unha serie crecente de facturas non pagadas que levaron a A.C.I. á creba e á ameaza constante de peche.

A crise foi capeada o primeiro ano polo propio Alfredo Sánchez Bella, persoa á que acudiron os directivos para obter cartos á marxe da subvención oficial.

7 O Director do Instituto de Cultura Hispánica, o Arcebispo de Compostela, Capitán Xeneral da VIII Rexión Militar, Almirante Capitán Xeneral do Departamento do Ferrol, Gobernador Civil da Provincia, Gobernador Militar da Praza, Presidente da Audiencia Territorial, Alcalde-Presidente do Concello, Presidente da Deputación, Comandante da Mariña, Presidente RAG, Presidente Academia Provincial de Belas Artes, Reitor USC, «Cuerpo consular hispanoamericano», representacións culturais «y señoritas participantes en el Congreso Femenino Hispanoamericano celebrado días antes en la capital de la nación» (A.C.I., 44843).

8 Non sucedeu así con outro mural de José María Labra, que permaneceu no Instituto de Provisión e foi trasladado ao Pazo de Mariñán. 
Pero o castigo non se fixo esperar e, en 1952, o I.C.H. reduciu á metade a subvención, deixándoa en 6 mil ptas. anuais, sempre que se enviase a Madrid unha relación exhaustiva dos gastos. Acoden daquela á Deputación e ao Concello, mesmo a procurar algunha subvención extra do Gobernador Civil, pero apenas teñen resposta, seica porque as institucións tiñan que centrarse, máis que nos cursos de verán da A.C.I., nos elevados gastos das visitas estivais de Franco e a súa muller.

\section{MANOBRA OFICIAL PARA DERROCAR OS ELEMENTOS BOHEMIOS E DESBALDIDORES.}

Desde Madrid, fartos da incompetencia da A.C.I. coruñesa para organizaren os gastos con racionalidade, recrimínanlles os excesos aos intelectuais e artistas que a rexían. Estes excesos escandalizaban os seus opoñentes no mesmo seo da Asociación, os membros do «Círculo de Estudos Migratorios», vinculados a Acción Católica e moi reaccionarios ${ }^{9}$-organizaban actos relixiosos, convites a cónsules, charlas de tipo social e económico. O Círculo figuraba inscrito na A.C.I. como unha entidade colaboradora, e achábase integrada polos chamados ex residentes, importantes en número, pois só na provincia da Coruña se contaban por centenares os paisanos retornados coa nacionalidade arxentina. Os nomes de Pascual Gantes de Boado -secretario da $1^{\mathrm{a}}$ Xunta Directiva-, Bernardo Barreiro, Luis Vázquez-Pena Núñez e Manuel Rodríguez Maneiro figuran no grupo dirixente.

Deste xeito, aos problemas económicos da A.C.I. uníronse os políticos e culturais, ben como o enguedello entre eles explica os vaivéns, disensións, baixas de socios e continuos cambios de directivos. Carlos Robles Piquer, que a principios dos 50 era Xefe de Información de Cultura Hispánica e Secretario da A.C.I. de Madrid, consideraba que na Coruña o Círculo demostrara un mellor funcionamento que a A.C.I. Terminou viaxando a Coruña en marzo de 1954 para lograr un acordo entre Juan González Cebrián, presidente daquela da A.C.I., e Luis Sánchez Mosquera, director do Círculo. A finalidade oculta era desbancar a directiva da A.C.I. e facer desaparecer o peso dos artistas para orientar as actividades da nova Asociación aos fins ideolóxicos do Réxime en materia de hispanización, a través da fundación dunha entidade na que se englobarían ambas sociedades e que se chamaría Casa de América.

Pero a estratexia encamiñada a facer desaparecer a A.C.I. baixo o peso do Círculo -á que Pascual Gantes de Boado pertencía, como xa vimos- remataría por fracasar ${ }^{10}$.

9 Acción Católica ten un Secretario Nacional de Migración. Os socios do Círculo adoitaban ofrecer conferencias de tema relixioso, e algunhas de ideoloxía retrógrada, como «Juan Donoso Cortés y Europa», pronunciada por Pascual Gantes de Boado o 5 de maio de 1953.

10 Dimite a directiva do Círculo en 1955. Desde Madrid ameazan con non concederen un peso máis. Pintos non logrou que o «Círculo de Estudios Migratorios», póla da A.C.I. presidida polo doutor Luis Sánchez Mosquera, continuase adscrito á A.C.I.. Por iso dimitiu. De aquí naceu unha escisión entre os «culturalistas puros» (que consideraban o Círculo como corpo estraño e alleo ao corpo «esencialmente cultural» da A.C.I.), e os «integracionistas», que aspiraban a que o Centro 
Houbo finalmente unha saída lenta dos números vermellos e das amezas de preitos da parte dos acredores, a partir do momento en que a A.C.I. deixou o local social en 1964 e pasou a ocupar o andar segundo da Casa da Cultura creada en 1956 no Xardín de San Carlos, onde Miguel González Garcés dirixía a Biblioteca Provincial. Despois de Enrique Míguez Tapia, e de Juan González Cebrián, Miguel González Garcés sería presidente da A.C.I. practicamente ata o seu peche, acompañado polo vicepresidente Antonio Molina. Só nos primeiros anos o poeta levou unha presidencia accidentada, debida aos seus despistes e desleixos, pero sobre todo por dar preponderancia á Casa da Cultura e quitar independencia á A.C.I., sempre resistente e celosa da súa personalidade. As disensións desaparecerían finalmente á medida que as subvencións medraban e os acredores se esvaecían.

\section{ACTIVIDADES DA A.C.I. CORUÑESA.}

As actividades da A.C.I. empezaron xa a finais de 1950, antes da inauguración oficial, con concertos (da Agrupación Albéniz), lecturas de inéditos literarios, charlas, conferencias -mesmo chega a anunciarse en xaneiro que vai dar unha conferencia José Ortega y Gasset en marzo-, e o Curso de Verán de 1951. Para este curso contouse cunha achega de 10 mil ptas. do I.C.H., que serviu para sufragar as leccións pronunciadas na Sala Magna do Palacio de Xustiza por Leopoldo Panero, José Luis Varela, Manuel Fraga Iribarne, Luis Rosales, Luis Monteagudo, Carlos Martínez Barbeito e o reverendo Padre Tamargo ${ }^{11}$. Coincidindo co curso, celebrouse nos salóns do Pazo Municipal a I Bienal de Arte Gallego, dirixida por Mariano Tudela coa asesoría artística de Urbano Lugrís. Tratábase dunha exposición selectiva de arte galega, previa á I Bienal Hispanoamericana de Arte que organizaba en Madrid o Instituto baixo a dirección de Leopoldo Panero. Expoñíanse obras de Antonio Lago Rivera, José María Labra, María Antonia Dans, Manuel Castro Gil, Julio Prieto Nespereira, Laxeiro, Julia Minguillón, Antonio García Patiño, Carlos Maside, Antón Tenreiro, Santiago Rey Pedreira, Antonio Faílde, Carlos Sobrino, Portela e Asorey. Foi clausurada por Franco durante a súa estadía de verán en Meirás.

A A.C.I. organiza tamén actos sociais como bailes e ceas de homenaxe, e nalgún intre hai queixas nas xuntas xerais sobre o escoramento perigoso cara a eventos caros -cómpre dicir que algúns son propiciados desde Madrid, que envía xente recomendada. Ás veces os bailes, como os de Entroido, serven para o contrario: para recadar cartos.

Mesmo organizan en febreiro unha viaxe a prezo módico, con saída o día 3 e regreso o día 8, para asistir en Madrid á inauguración da exposición de Salvador Dalí, e á retrospectiva de Goya, ambas colofón da Bienal. E alá van o res-

acollese non só as actividades migratorias, senón todo o que tivese que ver con Galicia e España en Hispanoamérica (Quesada, 1965).

11 Houbo un malentendido, con repercusión na prensa, que impediu que tivese lugar a disertación de Montero Díaz ( cfr. El Ideal Gallego, 28/07/1951, A.C.I. 44853). 
ponsable na executiva de exposicións, Mariano Tudela, acompañado do seu asesor artístico, Urbano Lugrís.

\section{A DERIVA ECONÓMICA}

Manuel Fraga Iribarne, que participa en xuño de 1952 con dúas conferencias na Coruña para celebrar o aniversario da creación do Instituto de Cultura Hispánica, promete arranxar os problemas económicos pendentes, que levaron ao corte de subministro por parte do I.C.H. Tras a «I Semana Iberoamericana», entre o 24 e o 31 de agosto, comeza o II Curso de verán da A.C.I., que esta vez conta coa participación de Gonzalo Torrente Ballester, Camilo Barcia Trelles, Benito Varela Jácome, Camilo José Cela, Valentín Paz Andrade, Miguel González Garcés, Ramón González Alegre, José María Castroviejo, Enrique Mariñas, Carlos Martínez Barbeito, Francisco Fernández del Riego, e Álvaro Cunqueiro. Como actividades complementarias, organízase unha excursión a Santiago con conferencia de Ángel del Castillo, e a asistencia á Xira dos Caneiros en Betanzos. O director do curso e reitor da Universidade de Santiago de Compostela, Luis Legaz Lacambra, tamén Delegado Provincial de Educación da FET e as JONS, clausura o curso con asistencia de alumnos hispanoamericanos.

Durante ese mesmo verán organízanse uns Xogos Florais que teñen como mantedor a Eugenio Montes, e como secretario a Mariano Tudela, acompañado na mesa por Camilo José Cela. Recibe a Flor Natural o poeta Gerardo Diego, que por unha confusión chega antes de tempo á cidade para o premio. $\mathrm{O}$ alcalde, Alfonso Molina, pídelle, sen éxito, que prolongue a súa estadía para estar presente no acto. Amólao a negativa do poeta e decide adiar o pago do premio ata febreiro de 1954.

Para maior confusión, algúns dos socios poñen cartos do seu peto para poder afrontar certos gastos ${ }^{12}$. Un ano despois, a Exposición de arte galega para a II Bienal, que se ía celebrar en agosto de 1953 baixo a dirección de José María Labra, con algún artista engadido ao grupo do ano anterior, como Isaac Díaz Pardo, queda fanada por falta de fondos e vense obrigados a devolver as obras.

A finais de 1954, Carlos Robles Piquer comunícalle ao novo presidente, Jesús Pintos, que deben indicar o criterio que seguen na A.C.I. para aplicar a subvención do I.C.H.: canto pagan por conferencias, recitais, etc., e se teñen por norma pagar outros gastos.

Paco Tudela, nunha entrevista inédita, explica como os cartos se desbaldían en grandes comedelas (as facturas que están arquivadas así o corroboran) con gran número de convidados (Tudela 2004). Sobre este particular, hai un artigo de Camilo José Cela que apunta a outro tipo de gastos: non sabemos se é pura literaturización da realidade ou se, en efecto, o descontrol chegou a ser deste calibre:

12 Quedan probas documentais, por exemplo, de que Paco Tudela anticipou arredor de 2 mil ptas. para completar o pago esixido por Eugenio Montes. E á finais de 1952 rexístrase o préstamo feito por Mariano Tudela, a quen se lle deben aínda 722 ptas. (A.C.I., 44847, 44848). 
«Una vez, en La Coruña, después del recital se fueron todos a cenar, se pusieron morados, bebieron hasta la embriaguez, moderada embriaguez, y se fueron de putas a casa de la Apacha, en la calle del Papagayo. En un aparte, el rapsoda le dijo a don Mariano Tudela, el autor de Torerillo de invierno: Dígame, doctor (el rapsoda llamaba doctores a los jóvenes literatos, que lo agradecían mucho), ¿la ocupadita, corre a cargo de la municipalidad?» (Cela 1992).

\section{CONFERENCIAS E ACTIVIDADES ANEXAS DE ÁLVARO CUNQUEI- RO NA A.C.I.}

Revisando a documentación sobre a A.C.I. advertimos que o pagamento de conferencias non se atiña a unha cantidade fixa. Habitualmente pagábanse 500 ptas. Pero había unha excepción chamada Álvaro Cunqueiro, que cobraba desde os primeiros anos 1000 ptas. A partir de 1969 o pagamento elévase a catro, cinco e ata seis mil ptas., aínda que contabilizadas como obsequios aboados á libraría Arenas.

Pasaron por Coruña conferenciando Gerardo Diego, Francisco Umbral, Ramón Otero Pedrayo, Paco del Riego, Silvio Santiago, Rodolfo López Veiga, Domingo García-Sabell, Juan Rof Carballo, Ramón Nieto, Manuel María, José María Moreno Galván, Celso Emilio Ferreiro e Xesús Alonso Montero, entre moitos outros. Houbo recitais de Arcadio López Casanova e Marina Mayoral, de Salvador García Bodaño, e de Manuel Álvarez Torneiro. Acudiron músicos portugueses entre os que estaba José Afonso, etc. Compróbase, á luz da documentación existente, que Álvaro Cunqueiro foi o conferenciante máis veces contratado pola A.C.I., malia non dispoñer de todos os datos ao respecto, pois o caos administrativo no que se mergullaba a A.C.I. por tempadas deixounos sen recoller. Desta documentación do Arquivo do Reino de Galicia extraemos a seguinte relación de actos que teñen a Cunqueiro como protagonista ou colaborador ${ }^{13}$ :

1952. Leccións impartidas no «Curso de Verano» os días 19 e 20 de agosto: «Temas del Cancionero Galaico-Portugués». «La pintura española actual».

1953. Lectura comentada, o 28 de agosto, do libro de inminente aparición, Siete contra Tebas, e recitado de poemas nados á calor desta obra.

Cea-homenaxe a Cunqueiro ás 11 da noite do 29 de agosto. Firman a convocatoria Pedro de Llano, Raúl Calvimontes, Francisco Pillado, Carlos Martínez Barbeito, Miguel G. Garcés, Álvaro Cebreiro, Antonio Couceiro Tovar, Luis J. Vázquez Pena, Mariano Tudela, Francisco Tudela, Fernando Mon e José María Labra.

13 O seguimento paralelo dos actos na prensa da época, que daba cumprida conta deles e mesmo entrevistaba a Cunqueiro, completaría esta relación. De feito, a documentación manexada inclúe numerosos retrincos de xornais. 
1954-1956. Sen datos. É o período marcado polo traballo na revista Atlántida, dirixida por membros da A.C.I., pero allea á entidade de maneira oficial. Máis adiante dáse conta do traballo de Cunqueiro nesta publicación.

1957. «El lenguaje de la literatura y las artes», conferencia. ${ }^{14}$

Participa o 25 de setembro na Homenaxe ao poeta gauchesco de Uruguai, nado en Ribadeo, José Alonso y Trelles, «El Viejo Pancho», canda Fernando Mon, Julio Sigüenza, Dionisio Gamallo Fierros e Glicerto Abarán.

1958 «Poesía y tierra de Uruguay», conferencia do 22 de agosto dedicada ao cónsul Julio Casal, que viviu na Coruña entre 1913 e 1927 e dirixiu, entre outras cabeceiras, Alfar.

1959 Conferencia no mes de maio.

Estrea o 31 de agosto, no teatro Colón, de $O$ incerto señor don Hamlet polo Teatro de Cámara da A.C.I., dirixido por Antonio Naveyra. $\mathrm{O}$ mesmo director organiza o 3 de novembro unha lectura dramatizada de Thornorn Wilder e Álvaro Cunqueiro.

1960 «Situación del lenguaje poético», conferencia do 29 de abril.

1962 «La palabra poética», conferencia do 30 de agosto, como clausura do Ciclo de Homenaxe a Ramón del Valle Inclán.

1963 «Vicente Risco y la nueva mitografía», conferencia do 23 de abril. «La imaginación, potencia creadora», conferencia do 24 de agosto. «Don Hamlet», nova representación, o 3 de setembro, seguida dunha Homenaxe a Cunqueiro.

1964 «Shakespeare vivo, 400 años después», conferencia no mes de abril. «Los mitos y el Padre Feijoo», conferencia no mes de agosto.

1965 «Rostros del Dante en el Camino de Santiago», conferencia no mes de agosto.

1967 «Estructuras del mundo mágico», conferencia no mes de setembro.

1969 Ás oito da tarde do 4 de marzo, celébrase un xantar-homenaxe no Hotel Atlántico pola obtención do Premio Nadal 1968 coa novela Un hombre que se parecía a Orestes. Antes, na Librería Arenas, Cunqueiro fai unha lectura comentada da obra antes de firmar exemplares. «Buscando el rostro del mundo», conferencia-recital, no mes de setembro ${ }^{15}$.

$1970 \ll$ «unción de la literatura», conferencia.

${ }^{14}$ O presidente, Miguel González-Garcés, alude en xunta celebrada o 12 de marzo de 1957, a unha carta na que Álvaro Cunqueiro se ofrece como conferenciante por 500 ptas. (oferta de prezo de amigo) e adianta o título (A.C.I., 44.844-36).

${ }^{15}$ No xornal di ser a primeira vez que fala en público da poesía propia. Explica que sempre escribiu poemas arredor das novelas que redactou. 
1971 «Algunas variaciones sobre Proust», conferencia no mes de agosto.

1972 «En el IV Centenario de Os Lusiadas», conferencia no mes de abril. Participa na mesa de presentación de Nas faíscas do soño, de Miguel González Garcés, con Francisco Pillado e o crítico literario e musical, Laureano Álvarez Martínez.

«Novalis, su vida y su obra», conferencia no mes de setembro. «Demonología y demonomagia con algunas brujas», conferencia no mes de decembro.

1975 «Varios retratos gallegos», conferencia no mes de xullo.

\section{PRESENZA DE ÁLVARO CUNQUEIRO NOUTRAS ACTIVIDADES CO- RUÑESAS DO ÁMBITO DA A.C.I.}

Recibíanse na sede social da A.C.I., xunto coas publicacións do I.C.H., unha serie de revistas que se achan na órbita da súa influencia: Alba, Aturuxo, Vida Gallega e Atlántida.

Esta última, publicada entre 1954 e 1956, é a máis relacionada coa institución, pois está dirixida e composta por membros da A.C.I. No ${ }^{\circ} 1$, Cunqueiro abre a entrega de separatas literarias, con «Crónica de la derrota de las naciones (fragmentos)», unha mestura de poemas bilingües, en prosa e en verso, sobre o tema da guerra. Tamén publica os traballos El gran teatro del mundo, Epístola de Santiago el Mayor, apóstol, a los peces del río Ulla, El huerto e Para cantar en maio a dona de abril, e finalmente, Mis memorias de don Ramón. Cómpre anotar tamén que se publica unha extensa recensión de Merlín e familia escrita por José Couceiro Tovar ${ }^{16}$.

Como actividades paralelas cómpre mencionar tamén a presenza de Cunqueiro nos programas emitidos por Radio Nacional, que dirixía eses anos o periodista e membro da A.C.I., Enrique Mariñas ${ }^{17}$.

Canto á representación escénica ou lida das súas pezas, hai que situalas no contexto das actividades teatrais no seo da A.C.I. Houbo na primeira Xunta Directiva un vogal de teatro, o técnico José Balboa Sánchez, que foi cesado en maio de 1952 por falta de actividade. Pasou a desempeñar o labor Antonio Naveyra Goday, avogado. Así créase en 1959 o Teatro de Cámara da A.C.I. de Coruña dentro do Círculo de Estudios Teatrales, que en 1960 é rexistrado oficialmente no Ministerio de Información y Turismo, con autonomía no seo da A.C.I. Esa autonomía servirá a Antonio Naveyra para expresarlle as súas queixas a Miguel González Garcés, ao que lle recriminaba que non mirase máis que polas

16

Traballos publicados, respectivamente, nos números: 3, maio-xuño de 1954: 3; 4-5-6, decembro de 1954: 5; 8, marzo-abril de 1955: 1 e 2; 13, xaneiro-febreiro de 1956: 6-7. A recensión de Tovar aparece no no 11-12, decembro de 1955: 22.

${ }^{17}$ Cfr. Cunqueiro, 1991; Braxe /Seoane, 1991. 
conferencias de verán, deixando postergado todo o relativo aos trámites e procura de subvencións para os actos teatrais.

Extraemos da documentación do Arquivo do Reino e Galicia as seguintes noticias sobre actividades do Teatro de Cámara:

1) Representación de Edipo abandonado, de José Luis López Cid en maio de 1954.

2) Tras a estrea en agosto de $O$ incerto señor don Hamlet o 3 de novembro de 1959, e como ilustración da conferencia de Antonio Naveyra, Precursores de la escena contemporánea, o grupo representa fragmentos de Nuestra ciudad, versión castelá da peza de Thornon Wilder, e de $O$ incerto señor don Hamlet, de Álvaro Cunqueiro.

3) Representación de Las sillas, versión castelá da obra de E. Ionesco en decembro de 1960.

4) Representación de Os vellos non deben de namorarse, na Praza de Touros, dentro dos «Festivales de España», o 14 de agosto de 1961. Antes estrearan a obra en Santiago de Compostela. A xuízo de Ramón Otero Pedrayo, a función en Compostela resultara mellor.

5) Representación de Ligazón e La rosa de papel (estrea absoluta en España desta última), no ciclo dedicado a Valle Inclán, o 29 de agosto de 1962.

6) Representación de La lección de E. Ionesco, o 29 de decembro de 1962.

7) Dramatizacións na Homenaxe a Ramón Gómez de la Serna, o 25 de xaneiro de 1963.

\section{FONTES DOCUMENTAIS}

ARCHIVO GENERAL DE LA ADMINISTRACIÓN DEL ESTADO, Cultura, 107 CA 482.

ARQUIVO DO REINO DE GALICIA, Cultura, «A.C.I.».

Armesto Faginas, X. F. (1991) Cunqueiro. Unha biografía, Vigo, Xerais.

Braxe, L. + Seoane, Xa. (eds.) (1991) A máxia da palavra. Cunqueiro na rádio. Crónicas, adaptacións, charlas, entrevistas e guións de Álvaro Cunqueiro en R.N.E., Santiago de Compostela, Sotelo Blanco.

Cabana, D. X. (2007) Cunqueiro e Don Hamlet en Lugo (San Froilán, 1959), Lugo, Concello de Lugo.

Cela, C. J. (1992) «El rapsoda», El camaleón soltero, Madrid, Grupo Libro 88, 1992 [reedición en Retorno a Iria Flavia, Santiago de Compostela, 2006: 138-139].

Cunqueiro, A. (1991) Cunqueiro en la radio. Cada día tiene su historia y otras series. Comentarios radiofónicos. Radio Nacional de España. A Coruña (1956-1981), A Coruña, Fundación Pedro Barrié de La Maza.

Cunqueiro, A. (1994) Entrevistas a Cunqueiro, edición a cargo de Ramón Nicolás Rodríguez, Vigo, Nigra. 
Cunqueiro, A. (2003) Cartas ao meu amigo. Epistolario mindoniense a Francisco Fernández del Riego (1949-1961), Vigo, Galaxia.

Gracia, J. (2008) La vida rescatada de Dionisio Ridruejo, Barcelona, Anagrama.

Guillot, V. (2007) «Mauro Muñiz, doctor en periodismo por la Universidad Complutense», lnes.es, Gijón, 5 de agosto.

http://www.Ine.es/gijon/1720/he-querido-periodicos-vayan-delante-pais/545716.html

Quesada, E. (1965) «La Asociación Cultural Iberoamericana», El Ideal Gallego, 17/01: 11-12.

Rodríguez González, O. (2004): «Entrevista a Paco Tudela», gravación inédita.

Tudela, M. (1991a) «Josep Pla y Cunqueiro: los más interesantes oradores periféricos», Xornal Diario, 17/05: 20.

Tudela, M. (1991b) «Álvaro Cunqueiro y La Coruña», La Coruña: 55-56. 